\title{
Avaliação preliminar do gasto de combustível em manobras de atitude de veículos espaciais
}

\author{
Maria Cecília Zanardi \\ Universidade Federal do ABC, UFABC \\ 09210-580, Santo André, SP \\ e-mail: mceciliazanardi@gmail.com \\ João V. L. França*, \\ UNESP - Campus de Guaratinguetá \\ 12516-410, Guaratinguetá, SP \\ E-mail: joao.v.l.franca@gmail.com
}

\begin{abstract}
$\underline{\text { RESUMO }}$
A orientação espacial (atitude) de um satélite artificial em relação a um sistema de referência é primordial para que a missão espacial a que ele se destina atinja seus objetivos. Neste trabalho é discutido o consumo de combustível necessário em manobras de atitude, com a atitude descrita pelos ângulos de Euler da sequência 3-1-3 e pelas componentes da velocidade de rotação no sistema fixo no satélite $[3,4]$.

As simulações de manobras de atitude são realizadas com o software MATLAB, utilizando o método de Runge Kutta de $4^{\mathrm{a}}$ ordem para integrar as equações cinemáticas e dinâmicas [3, 4], nas quais estão incluídas as parcelas do torque de controle propulsivo.

As magnitudes dos torques de controle utilizados são avaliadas de modo que sejam suficientes para a mudança dos parâmetros da atitude do satélite de valores iniciais a valores finais previamente estabelecidos.

Para avaliar o gasto de combustível é considerado que as manobras são instantâneas, sendo necessário conhecer o incremento da velocidade linear devido às variações na velocidade de rotação durante a manobra de atitude.

Aplicações são realizadas para os dados do Satélite de Coleta de Dados Brasileiro SCD2 [2]. Os resultados [1] apontam que para manter erros de desvio de atitude da ordem de $0,5^{\circ}$ nos ângulos envolvidos e de $0.5 \mathrm{rpm}$ na velocidade de rotação, é necessário que as magnitudes do torque sejam da ordem de dezenas $\mathrm{Nm}$. Em consequência é necessário um alto gasto de combustível [1], maior do que $10 \mathrm{~kg}$, o que inviabiliza uma aplicação prática do controle. Para obter valores com maior praticidade é necessário que os erros de atitude aceitáveis sejam da ordem de $1^{\circ}$, o que nem sempre é aceitável em missões espaciais.

Saliente-se que as aplicações foram realizadas para um satélite de pequeno porte e que nenhum sistema de controle foi adicionado nas manobras Os resultados poderiam ser mais viáveis se aplicadas para satélites de maior dimensão e com a introdução de sistemas de controle na análise a ser realizada.

A abordagem realizada estabelece diretrizes a serem utilizadas para a avaliação inicial de torques de controle e do gasto de combustível necessários em manobras de manutenção de atitude de veículos espaciais.
\end{abstract}

Palavras-chave: Manobras de atitude, torque de propulsão, gasto de propelente.

\section{Referências}

[1] França, J. V. L., "Manobras de Atitude de Satélites Artificiais", Relatório final de Bolsa de iniciação Cientifica Junior, UNESP - Campus de Guaratinguetá 2013. 
[2] Prado, A. F. B. A; Kuga, H. K., "Fundamentos de Tecnologia Espacial”, INPE, São José dos Campos, 2001.

[3] Zanardi, M. C., “Fundamentos de Astronáutica”, Apostila do ITA, 1990.

[4] M. C. Zanardi,'Dinâmica da Atitude de Satélites Artificiais", Tese de Livre Docência, UNESP - Campus de Guaratinguetá, 2005. 